\title{
Экологическое право
}

\section{Китайское экологическое чудо China's environmental miracle}

\author{
Д. В. Спиридонов, \\ кандидат юридических наук, \\ доцент кафедры экологического и природоресурсного права \\ Московского государственного юридического университета \\ имени О.Е. Кутафина (МГЮА), Россия \\ dvspiridonovamsal.ru \\ D. V. Spiridonov, \\ Cand. Sci. (Law), \\ Kutafin Moscow State Law University (MSAL), Russia \\ dvspiridonovdamsal.ru
} Associate Professor of the Department of Environmental and Natural Resource Law,

(ㄷ) Д. В. Спиридонов, 2021

DOI: $10.17803 / 2587-9723.2021 .4 .146-150$

\begin{abstract}
Аннотация. Данная работа посвящена анализу большого прорыва Китая в сфере охраны окружающей среды. За последние годы страна сделала колоссальные усилия, чтобы способствовать снижению антропогенного фактора на экологию: стала передовым производителем расходных материалов в сфере «зеленой» энергетики, включила экологию в план стратегического развития, скорректировала налоговую систему, что позволило в итоге добиться грандиозных результатов и считать эти масштабные преобразование настоящим чудом, заслуживающим внимания в аспекте перенимания опыта.
\end{abstract}

Ключевые слова: Китай, экология, «зеленая энергетика», снижение выбросов, эмиссия $\mathrm{CO}_{2}$, загрязнение воздуха, ВИЭ, энергетический переход, загрязнение окружающей среды.

Abstract. The article is devoted to the analysis of China's great breakthrough in the field of environmental protection. In recent years, the country has made enormous efforts to help reduce the anthropogenic impact on the environment: it has become an advanced manufacturer of consumables in the field of "green" energy, has included the environment in the strategic development plan, adjusted the tax system, which has allowed us to achieve great results and consider these large-scale transformations a real miracle, worthy of attention in the aspect of learning from experience.

Keywords: China, ecology, green energy, emission reduction, $\mathrm{CO} 2$ emissions, air pollution, renewable energy sources, energy transition, environmental pollution.

$\mathrm{C}$ егодня Китайская Народная Республика выступает самым большим производителем товаров во всем мире, производственной площадкой для стран Европы, которые предпочли перенести свои фабрики и заводы туда ввиду экономической выгоды, в том числе чтобы снизить экологическую нагрузку на свои страны.

Из-за постоянного использования своих производственных мощностей Китай выступает крупнейшим загрязнителем окружающей среды в мире. Ученые отмечают, что КНР лидирует по выбросам диоксида серы в атмосферу, способствует загрязнению рек, морей, подземных вод, опустыниванию и росту болезней в мире, вызванных неблагоприятной окружающей средой ${ }^{1}$. Несмотря на то, что в стране проживает лишь $18 \%$ мирового населения, страна потребляет 28 \% всего топлива на планете ${ }^{2}$.

Ван Шивэй, Ясовеев М. Г. Экологическая политика Китая //Экологический вестник. 2016. № 1 (35). С. 15-19.

2 Деньги из воздуха: как Китай развивает «зеленую» энергетику // URL: https://nangs.org/news/renewables/denygiiz-vozduha-kak-kitay-razvivaet-zelenuyu-energetiku (дата обращения: 15.04.2021). 
Долгие годы КНР рассматривали как «экономическое чудо», так как из отсталой страны третьего мира он в рекордно короткие сроки превратился в успешную, экономически развитую страну. Стремительное развитие Китая за последние три десятилетия вывело сотни миллионов людей из нищеты и привело страну в ряды крупнейших экономик мира. Но данное развитие требует нескончаемых источников энергии.

В течение следующих нескольких десятилетий по мере того, как экономика Китая продолжат расти, а темпы урбанизации ускоряются, страна должна не только обеспечить достаточное и надежное энергоснабжение, но и смягчить воздействие такого роста на окружающую среду.

В последнее время Китай стремится удивить мировую общественность еще больше, так как, несмотря на активную нагрузку на экологию изза непрекращающегося производства различных товаров, страна делает все возможное, чтобы эту нагрузку снизить.

Китай настолько серьезно сделал рывок в использовании альтернативных источников энергии, что в настоящее время можно с уверенностью сказать, что на наших глазах происходит новое, уже «экологическое чудо».

В контексте стратегического развития Китая сокращениям выбросов в атмосферу отводится значимая роль. Так, в своем интервью Председатель КНР Си Цзиньпин предполагает максимальное снижение выбросов $\mathrm{CO}_{2}$ до 2030 г., а к 2060 г. достичь углеродной нейтральности ${ }^{3}$. Правительство страны также анонсировало сокращение вредных выбросов, отказ от угля в пользу газа и другие важные меры.

Китай строит свои стратегические планы в соответствии с разрабатываемыми пятилетками развития страны. Впервые об экологии правительство страны заговорило еще в 2006 г., с тех пор каждые пять лет Китай ставил все более масштабные планы по снижению антропогенной нагрузки на экологию.

В 2016 г. он ратифицировал Парижское соглашение ${ }^{4}$, по которому страны-участницы обязуются ввести регулирующие меры для снижения содержания углекислого газа в атмосфере.
Можно выделить следующие шаги, предпринимаемые страной в рамках «зеленой» экологической стратегии ${ }^{5}$ :

1. Снижение количества потребляемого угля. Китай предпринял шаги по демонтажу старых электростанций, работающих на сжигании угля, снижению общего уровня выбросов и снижению уровня выбросов твердых частиц в частности. Огромный прогресс был достигнут в области качества воздуха, и теперь в крупнейших городах Китая стало меньше дней смога.

При этом Китай не отказался от использования угля как такового. Например, в 2016-2017 гг. введены в эксплуатацию две угольные ТЭС в пригородах Пекина. Принципиальное отличие от ранее действовавших ТЭС в том, что они построены в соответствии с новыми китайскими экологическими стандартами, которые ужесточают требования по выбросам оксидов азота, оксидов серы и золы. Например, по золе предельная концентрация сократилась более чем в 300 раз, тем самым стандарты стали более жесткие, чем в странах Европейского Союза ${ }^{6}$.

2. Совершенствование администрирования в области охраны окружающей среды. Благодаря реформированию создан новый аппарат по надзору и контролю в сфере охраны и защиты окружающей среды - Министерство экологии и окружающей среды. Новое Министерство будет контролировать всю политику, связанную с водными ресурсами, — от управления океанскими ресурсами до подземных вод. Раньше они были разбросаны по разным отделам. Министерство также отвечает за политику в области изменения климата ${ }^{7}$.

Интересным нововведением является то, что прямо на официальном сайте Министерства экологии и окружающей среды в режиме реального времени публикуются отчеты о загрязненности воздуха в выбранном городе (см. рисунок).

Подобная политика позволяет простым людям видеть и контролировать уровень загрязнений.

3. Финансирование более «зеленого» будущего. Так как строительство новых экологических проектов требует дополнительного финансирования, в Китае с 2018 г. введен новый экологический налог.

3 Эковыбор Китая: как страна (с трудом) пытается отказаться от неразлагаемого пластика // URL: https://tass.ru/ mezhdunarodnaya-panorama/10334823 (дата обращения: 20.04.2021).

4 Парижское соглашение 2015 г., принятое в рамках Конвенции об изменении климата // URL: https://www.un.org/ ru/climatechange/paris-agreement (дата обращения: 10.04.2021).

5 The Outline of the 13th Five-Year Plan for National Economic and Social Development of the People's Republic of China URL: http://www.sdpc.gov.cn/fzgggz/fzgh/zhdt/ghwb/gjjh/201603/ P020160318564052484043.pdf (дата обращения: 15.04.2021).

6 Хохлов А. Очищение угля: чему Россия может поучиться у Китая // URL: https://www.rbc.ru/opinions/business/21/1 2/2018/5c1b7e439a7947f76c69db2b (дата обращения: 20.04.2021).

7 Официальный сайт Министерства экологии и окружающей среды. URL: https://english.mee.gov.cn/ (дата обращения: 15.04.2021). 
Beijing [Switch] 04/21/2021 16:00

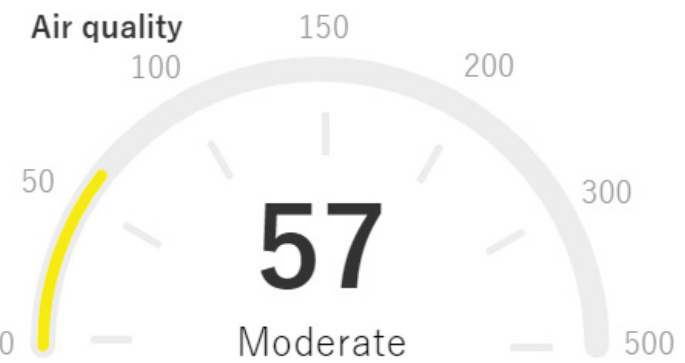

Members of sensitive groups should reduce outdoor activities.

Puc. Уровень загрязнений воздуха

По мнению создателей и разработчиков данного нововведения, это первый в Китае налог, который направлен именно на защиту окружающей среды, его размер зависит от региона налогоплательщика ${ }^{8}$.

Особенностью налога является то, что, в отличие от ранее действовавшего согласно Положению Государственного совета КНР от 2 января 2003 г. «О порядке взимания платы за загрязнение окружающей среды» налога, этот налог должен взиматься в местный бюджет ${ }^{9}$, что поможет распределить ресурсы на восстановление окружающей среды более гармонично.

Налог на охрану окружающей среды имеет различные налоговые ставки в зависимости от уровня загрязнения, а это означает, что предприятиям, которые являются масштабными загрязнителями природы, придется платить больше, чем тем, кто сократил количество своих выбросов, что будет стимулировать предприятия снижать нагрузку на экологию.

Закон затронет как индустриальные компании, так и частных лиц. Согласно оценкам аналитиков, новый налог позволит ежегодно собирать до 50 млрд юаней (около 7,68 млрд долл. США) ${ }^{10}$, которые правительство намерено направить на улучшение экологической обстановки страны.

Инвесторам следует ожидать дальнейших шагов китайского правительства в области ох- раны окружающей среды, хотя и постепенных, поскольку местные органы власти пытаются уравновешивать требования экономического роста и экологические проблемы.

4. Снижение производства пластика. В январе 2020 г. власти КНР обнародовали план отказа от неразлагаемого пластика в определенных сферах и его замены на новые материалы к концу 2025 г.

Данный посыл звучит очень оптимистично, ведь о том, что белый пластик не разлагается и наносит непоправимый вред природе и окружающей среде, учат даже в школах.

Министерство экологии и окружающей среды КНР выпустило руководство по запрету использования таких изделий, как пластиковые пакеты, одноразовая пенопластовая посуда, пластиковые ватные тампоны, бытовая химия, содержащая пластиковые микробы, трубочки для коктейлей и другие неразлагаемые пластмассы ${ }^{11}$. Продажа и производство одноразовой пенопластовой посуды и пластиковых ватных тампонов будут запрещены до конца текущего года. Указанный проект будет реализован в несколько этапов и полностью вступит в силу к концу 2025 г.

Но это не обязательно будет работать так, как предполагалось, такой позиции придерживается и Гринпис, в своем Докладе 2020 года о биоразлагаемом пластике эксперты отмечают, что, если производство биоразлагаемых пластмасс продолжится в таком же объеме, китайская индустрия электронной коммерции будет генерировать около 5 млн тонн биоразлагаемых пластиковых отходов в год к 2025 г. ${ }^{12}$

Следовательно, если политика приведет к простому переходу на компостируемый пластик, без массовых инвестиций в технологию компостирования и инфраструктуру, это по факту создаст лишь массовые проблемы с мусором. Реальные изменения требуют изменения культуры использования того же пластика, а не только применения различных материалов.

5. Создание зон устойчивого развития. Принимая во внимание Повестку дня ООН в области устойчивого развития на период до 2030 года ${ }^{13}$, китайское правительство утвердило три зоны

8 Закон КНР «О налоге на загрязнение окружающей среды».

9 Кранина Е.И. Экологическая реформа КНР в 13-й пятилетке (2016-2020 гг.) // 13-я пятилетка (2016-2020 гг.) важнейший этап построения в Китае общества малого благоденствия «сяокан». М., 2018. С. 138-139.

10 Китай ввел экологический налог // URL: https://novostipmr.com/ru/news/18-01-03/kitay-vvyol-ekologicheskiy-nalog (дата обращения: 15.04.2021).

${ }^{11}$ China to ban single-use non-degradable plastic to reduce waste // URL: https://www.packaging-gateway.com/news/ china-ban-single-use-non-degradable-plastic/ (дата обращения: 17.04.2021).

12 Доклад Гринпис 2020 года о биоразлагаемом пластике // URL: https://www.greenpeace.org/static/planet4-eastasiastateless/84075f56-biodegradable-plastics-report.pdf (дата обращения: 15.04.2021).

13 Преобразование нашего мира : Повестка дня в области устойчивого развития на период до 2030 года // Резолюция, принятая Генеральной Ассамблеей 25 сентября 2015 года // URL: https://undocs.org/ru/A/RES/70/1 (дата обращения: 20.04.2021). 
устойчивого развития, которые будут способствовать реализации данной Повестки:

- Шэньчжэнь - это инновационный двигатель Китая. Эта зона будет интегрировать технологии очистки сточных вод, утилизации отходов, восстановления окружающей среды и искусственного интеллекта для решения вопросов от управления ресурсами до загрязнения окружающей среды;

- Гуйлинь - эта зона будет сосредоточена на инновациях, направленных на борьбу с опустыниванием, создавая решения, которые могут быть воспроизведены другими регионами, сталкивающимися с угрозой вторжения пустынь;

- Тайюань - эта зона, ориентированная на борьбу с загрязнением воздуха и воды, будет способствовать инновационным решениям, которые могут быть воспроизведены регионами, полагающимися на добычу ресурсов.

6. И, разумеется, развитие «зеленой» энергетики, которой принадлежит значимая роль в системе китайской экологии. Правительство Китая проанализировало экологические и экономические перспективы возобновляемых источников энергии (далее - ВИЭ) и сделало на них ставку в контексте плана промышленной модернизации лидера Китая Си Цзиньпина «Сделано в Китае - 2025», целью которого является доведение Пекина до мирового лидерства в сфере высоких технологий.

Правительство поставило цель увеличить общую долю солнечной и ветровой энергии в общем энергобалансе почти до 30 \% к 2030 г. ${ }^{14}$, что является феноменальным показателем, учитывая численность населения и масштабы производства в стране.

Всего, по данным Национального энергетического управления страны NEA, на конец 2020 г. суммарная мощность ветровой энергетики Китая составила 281,5 ГВт, солнечной $-253,4$ ГВт. Власти страны планомерно увеличивают долю генерации электростанциями на возобновляемых источниках энергии (ВИЭ): в 2005 г. она составляла всего 6,8 \%, на конец 2020 г. - 15 \%, а к 2030 г. должна достигнуть $25 \%$. Суммарная мощность ветровых и солнечных электростанций к этому моменту составит 1200 ГВт $^{15}$.
Мало того, что Китай сам активно использует свои ветряные турбины и панели, он стал мировым лидером по их производству. Так, уже по состоянию на 2017 г. 71 \% рынка солнечных панелей занимали китайские компания, при этом доля бывшего лидера в этой сфере Японии снизилась до $2 \%$, что является показателем «экологического» И «экономического» чуда в действии ${ }^{16}$.

Аналогичную ситуацию можно проследить и на рынке производства ветряных турбин: Китай является безусловным лидером, далее следуют Дания, Испания и США.

7. Международное партнерство в сфере «зеленой» энергетики. Международное агентство по возобновляемым источникам энергии (IRENA) и Государственная сетевая корпорация Китая (SGCC) подписали в 2020 г. новый Меморандум о взаимопонимании (MoU), в рамках которого обе организации будут тесно сотрудничать в целях поддержки модернизации сетей, гибкости систем и взаимодействия секторов в регионах Китая и коридора чистой энергии IRENA.

В рамках этого соглашения данные организации будут тесно сотрудничать, чтобы поддержать создание благоприятных условий для будущей энергетической системы, в которой доминируют возобновляемые источники энергии. Это партнерство представляет собой широко приветствуемые общие усилия по созданию декарбонизированной глобальной энергетической системы ${ }^{17}$. Данные направления разработаны в соответствии с Парижским соглашением, регулирующим меры по снижению содержания углекислого газа в атмосфере с 2020 г.

Подводя итоги, можно отметить, что, несмотря на то, что Китай внедряет «зеленую энергетику», прежде всего, разумеется, из-за того, чтобы снизить нагрузку на экологию страны, в конечном итоге его действия могут помочь всей планете, так как позволят существенно сократить количество выбросов в атмосферу, а следовательно, произойдет снижение загрязнений тех же пресных водоемов и уменьшение энергетической нагрузки в целом.

Как видим, действия Китая носят комплексный характер, разработана масштабная стратегия, которую страна активно выполняет, соблюдая баланс между экономикой и экологией.

\footnotetext{
14 Деньги из воздуха: как Китай развивает «зеленую» энергетику // URL: https://nangs.org/news/renewables/denygiiz-vozduha-kak-kitay-razvivaet-zelenuyu-energetiku (дата обращения: 20.04.2021).

15 В 2020 году ввод новых ВЭС в Китае почти втрое превысил показатель 2019 года // URL: https://rawi.ru/2021/01/v2020-godu-vvod-novyih-ves-v-kitae-pochti-vtroe-prevyisil-pokazatel-2019-goda/.

16 Деньги из воздуха: как Китай развивает «зеленую» энергетику // URL: https://nangs.org/news/renewables/denygiiz-vozduha-kak-kitay-razvivaet-zelenuyu-energetiku (дата обращения: 20.04.2021).

17 Официальный сайт Международного агентства по возобновляемым источникам энергии. URL: https://www.irena. org/newsroom/pressreleases/2021/Apr/IRENA-and-China-State-Grid-Agree-to-Advance-Transition-Through-PowerSystems-Enhancements (дата обращения: 10.04.2021).
} 
Позиция Китая в целом соответствует сложившейся во всем цивилизованном мире концепции проведения масштабных преобразований в рамках охраны окружающей среды, которые помогут восстановить повреждения окружающей природной среды, сократить количество антропогенной нагрузки и улучшить экологическую обстановку.

\section{БИБЛИОГРАФИЯ}

1. В 2020 г. ввод новых ВЭС в Китае почти втрое превысил показатель 2019 года // URL: https://rawi. ru/2021/01/v-2020-godu-vvod-novyih-ves-v-kitae-pochti-vtroe-prevyisil-pokazatel-2019-goda/.

2. Ван Шивэй, Ясовеев М. Г. Экологическая политика Китая // Экологический вестник. - 2016. - № 1 (35). С. $15-19$.

3. Деньги из воздуха: как Китай развивает «зеленую» энергетику // URL: https://nangs.org/news/renewables/ denygi-iz-vozduha-kak-kitay-razvivaet-zelenuyu-energetiku (дата обращения: 15.04.2021).

4. Деньги из воздуха: как Китай развивает «зеленую» энергетику // URL: https://nangs.org/news/renewables/ denygi-iz-vozduha-kak-kitay-razvivaet-zelenuyu-energetiku (дата обращения: 20.04.2021).

5. Доклад Гринпис 2020 года о биоразлагаемом пластике // URL: https://www.greenpeace.org/static/planet4eastasia-stateless/84075f56-biodegradable-plastics-report.pdf (дата обращения: 15.04.2021).

6. Китай ввел экологический налог // URL: https://novostipmr.com/ru/news/18-01-03/kitay-vvyolekologicheskiy-nalog (дата обращения: 15.04.2021).

7. Кранина Е. И. Экологическая реформа КНР в 13-й пятилетке (2016-2020 гг.) // 13-я пятилетка (20162020 гг.) - важнейший этап построения в Китае общества малого благоденствия «сяокан». - М., 2018. C. $138-139$.

8. Хохлов А. Очищение угля: чему Россия может поучиться у Китая // URL: https://www.rbc.ru/opinions/bus iness/21/12/2018/5c1b7e439a7947f76c69db2b (дата обращения: 20.04.2021).

9. Эковыбор Китая: как страна (с трудом) пытается отказаться от неразлагаемого пластика // URL: https:// tass.ru/mezhdunarodnaya-panorama/10334823 (дата обращения: 20.04.2021).

10. China to ban single-use non-degradable plastic to reduce waste // URL: https://www. packaging-gateway. com/news/china-ban-single-use-non-degradable-plastic/ (дата обращения: 17.04.2021).

11. The Outline of the 13th Five-Year Plan for National Economic and Social Development of the People's Republic of China // URL: http:/www.sdpc.gov.cn/fzgggz/fzgh/zhdt/ghwb/gjjh/201603/P020160318564052484043.pdf (дата обращения: 15.04.2021). 